\title{
Lipid changes in Duchenne muscular dystrophy
}

\author{
B. P. HUGHES \\ From the Muscular Dystrophy Research Laboratory, Institute of Neurology, \\ The National Hospital, London
}

SUMMARY Thin layer chromatographic analysis of lipid extracts of rectus abdominis and gastrocnemius muscles from controls and patients with severe sex-linked Duchenne muscular dystrophy shows the dystrophic tissue to contain more sphingomyelin, less lecithin plus choline plasmalogen, and more total cholesterol than normal. Comparison of normal, dystrophic, and immature muscle suggests that these observations can be interpreted as showing a similarity between dystrophic and immature muscle and in this respect human Duchenne dystrophy resembles hereditary muscular dystrophy in the mouse. Although sphingomyelin was present in apparently normal amount in muscle biopsies from patients with various other neuromuscular disorders, it was raised in two cases showing evidence of peripheral neuropathy.

Phospholipid abnormalities, chiefly a decrease in lecithin and an increase in sphingomyelin, have been demonstrated in hereditary muscular dystrophy of the mouse (Hughes, 1965), and it was later shown (Owens and Hughes, 1970) that the alterations in whole tissue phospholipid composition were mainly due to changes in a muscle microsome fraction.

The results given in this paper are based on the analysis of biopsy samples of muscle from young patients with Duchenne muscular dystrophy in whom muscle histological changes, and in particular fatty infiltration, were only moderate. They show that phospholipid abnormalities are present which are qualitatively similar to those found in the mouse disease.

\section{METHODS}

CLINICAL AND CONTROL MATERIAL Biopsies were obtained from the rectus abdominis and gastrocnemius (lateral head) muscles of patients with severe sex-linked (Duchenne) muscular dystrophy, aged 3 to 5 years.

Controls for the rectus abdominis muscle were obtained in the course of routine abdominal operations. However, it was not possible to obtain suitable control biopsies for the gastrocnemius muscle, so that in this case post mortem material was used.

Histological changes in the dystrophic specimens were at an early stage and, particularly in the case of the rectus abdominis muscle, fatty infiltration was not marked. This was confirmed by visual compari $\infty$ son of the triglyceride zones in the thin laye chromatograms of the dystrophic muscle lipie extracts with that of the controls. In some of the gastrocnemius specimens, although there was as increase in neutral lipid it was much less marke than in older patients, where overloading of the thin-layerplate with neutral lipid can impair separa tion of the phospholipids and distort the chromatogram unless an initial separation is carried out.

In addition to biopsies from young patients with severe Duchenne dystrophy, biopsies of various muscles from patients with other neuromuscular disorders were also examined.

METHOD Lipid extracts were prepared from tissue frozen in liquid nitrogen as already described (Owens and Hughes, 1970).

Quantitative thin-layer chromatography was carried out using the two-dimensional technique of Owens (1966) which permits the separate determination of choline and ethanolamine plasmalogen. ${ }^{1}$

Total cholesterol was estimated by the method of $\delta$ Zlatkis, Zak, and Boyle (1953) as modified by Owens and Hughes (1970).

1 Choline and ethanolamine plasmalogen are the aldehydogenic phospholipids in which one of the two hydrocarbon chains is attached to the glycerol moiety of the molecule by an unsaturated ether $N$ linkage, the other is attached by a fatty acid ester linkage. They correspond to lecithin (phosphatidyl choline) and phosphatidyl $N$ ethanolamine in which both chains are joined by ester links. 


\section{RESULTS}

TOTAL LIPID PHOSPHORUS Table 1 shows the total lipid phosphorus content of muscle from patients and controls on a wet weight basis. There is no significant difference between patients and controls for the two muscles examined.

PHOSPHOLIPID COMPOSITION Table 2 gives results for the phospholipid composition of normal and dystrophic human rectus abdominis and

TABLE 1

LIPID PHOSPHORUS IN HUMAN MUSCLE

\begin{tabular}{llc}
\hline Group & Muscle & $\begin{array}{c}\text { Lipid-P } \\
(\mu g / g \text { wet } w t .)\end{array}$ \\
\hline Normal & Rectus abdominis & $283 \pm 37$ \\
Dystrophic & Rectus abdominis & $286 \pm 22$ \\
Normal & Gastrocnemius & $339 \pm 52$ \\
Dystrophic & Gastrocnemius & $284 \pm 47$ \\
\hline
\end{tabular}

Means and standard deviations are based on analysis of five specimens in each group.

None of the differences is significant $(P>0 \cdot 05)$.

gastrocnemius muscles for individuals aged 3 years or older. In addition, values are presented for normal infants of ages ranging from 2 days to 15 months, together with data for pooled limb muscle from foetuses aged approximately 10 to 20 weeks. Data for phosphatidyl serine and monophosphoinositide are omitted for simplicity, since there were no consistent differences for these phospholipids between any of the groups examined. Lysolecithin was present only in trace amounts in biopsy material and did not exceed $3 \%$ of the total in tissue obtained post mortem. The cardiolipin fraction may contain some phosphatidic acid, although chromatography of human muscle extracts in a solvent (chloroform/methanol/7N. $\mathrm{NH}_{3}$ 60:35:5) by which the two phospholipids are well separated suggests that the phosphatidic acid content is low; a result in accordance with the findings of Rouser, Nelson, Fleischer, and Simon (1968).

Table 2 indicates that there are differences in the phospholipid composition of normal human muscle at different stages of development, although the times at which individual phospholipids attain their 'mature' values may vary. Thus at birth the amount of sphingomyelin and lecithin plus choline plasmalogen in both rectus abdominis and gastrocnemius are similar to that of 10 to 20 week foetal muscle and the subsequent fall in sphingomyelin and rise in lecithin plus choline plasmalogen occurs after birth. Ethanolamine phospholipid in the rectus abdominis muscle apparently does not change during development, but gastrocnemius muscle from the 5 to 40 year old normal group contains somewhat less ethanolamine phospholipid than tissue from younger individuals. The cardiolipin fraction increases during development but, by contrast with sphingomyelin and lecithin plus choline plasmalogen, some of the increase occurs partly before and partly after birth. In the case of the rectus abdominis muscle the increase appears to be complete by 6 months.

TABLE 2

PHOSPHOLIPID COMPOSITION OF HUMAN MUSCLE ((PHOSPHOLIPID-P AS \% TOTAL LIPID-P)

\begin{tabular}{|c|c|c|c|c|c|c|}
\hline Group & Muscle & Age & Sphingomyelin & $C P$ & $E P$ & Cardiolipin \\
\hline $\begin{array}{l}\text { Normal } \\
\text { Dystrophic } \\
\text { Normal } \\
\text { Normal } \\
\text { Normal } \\
\text { Normal } \\
\text { Dystrophic } \\
\text { Normal } \\
\text { Normal } \\
\text { Normal }\end{array}$ & $\left\{\begin{array}{l}\text { Rectus abdominis } \\
\text { Gastrocnemius } \\
\text { Foetal }\end{array}\right.$ & $\begin{array}{l}4-12 \text { yr (5) } \\
3-5 \text { yr }(5) \\
1 \mathrm{yr} \\
6 \mathrm{mth} \\
2 \mathrm{~d} \\
5-40 \mathrm{yr}(5) \\
3-5 \mathrm{yr}(4) \\
15 \mathrm{mth} \\
3 \mathrm{~d} \\
10-20 \mathrm{wk}(5)\end{array}$ & $\begin{array}{c}4 \cdot 8 \pm 0 \cdot 5^{*} \\
8 \cdot 2 \pm 0 \cdot 8^{*} \\
5 \cdot 7 \\
6 \cdot 7 \\
8 \cdot 8 \\
5 \cdot 4 \pm 1 \cdot 1 \dagger \\
7 \cdot 3 \pm 0 \cdot 3 \dagger \\
\frac{4 \cdot 7}{9 \cdot 7} \\
9 \cdot 2 \pm 2 \cdot 1\end{array}$ & $\begin{array}{c}53 \cdot 1 \pm 1 \cdot 5 \ddagger \\
50 \cdot 2 \pm 2 \cdot 0_{+}^{\ddagger} \\
51 \cdot 4 \\
50 \cdot 8 \\
48 \cdot 5 \\
53 \cdot 6 \pm 2 \cdot 0^{*} \\
48 \cdot 9 \pm 1 \cdot 0^{*} \\
48 \cdot 1 \\
49 \cdot 6 \\
49 \cdot 7 \pm 1 \cdot 1\end{array}$ & $\begin{array}{c}24 \cdot 7 \pm 2 \cdot 2 \\
24 \cdot 3 \pm 1 \cdot 1 \\
24 \cdot 2 \\
25 \cdot 4 \\
24 \cdot 4 \\
21 \cdot 4 \pm 1 \cdot 8^{*} \\
26 \cdot 7 \pm 1 \cdot 8^{*} \\
26 \cdot 8 \\
26 \cdot 3 \\
26 \cdot 0 \pm 2 \cdot 1\end{array}$ & $\begin{array}{c}7 \cdot 8 \pm 1 \cdot 3 \\
6 \cdot 2 \pm 1 \cdot 9 \\
6 \cdot 4 \\
7 \cdot 2 \\
4 \cdot 2 \\
7 \cdot 3 \pm 1 \cdot 2 \\
7 \cdot 5 \pm 1 \cdot 2 \\
8 \cdot 3 \\
4 \cdot 9 \\
2 \cdot 4 \pm 1 \cdot 2\end{array}$ \\
\hline
\end{tabular}

Values are given, where applicable, as mean \pm standard deviation.

$\mathrm{CP}=$ lecithin plus choline plasmalogen.

EP $=$ total ethanolamine phospholipid.

Difference between normal and dystrophic means significant with: ${ }^{*} 0.01>\mathrm{P}, \dagger 0.02>\mathrm{P}>0.01, \ddagger 0.05>\mathrm{P}>0.02$. (Student's $t$ test) 
Compared with normal muscle both dystrophic rectus abdominis and gastrocnemius muscles contain more sphingomyelin and less lecithin plus choline plasmalogen and in this respect resemble immature tissue. The content of these two phospholipids in the dystrophic rectus abdominis muscle does not differ significantly from that found in foetal muscle, whereas the amount of sphingomyelin in the dystrophic gastrocnemius muscle was intermediate between the normal gastrocnemius and normal foetal tissue. The ethanolamine phospholipid content of the dystrophic gastrocnemius is similar to that of immature muscle. Both the dystrophic muscles contain normal amounts of cardiolipin.

MUSCle PlaSmalogens Table 3 presents values for choline plasmalogen and ethanolamine plasmalogen which show that during development the percentage of choline plasmalogen increases, whereas the proportion of the ethanolamine plasmalogen changes little. It is possible that the rectus abdominis muscle contains somewhat more ethanolamine plasmalogen than does the gastrocnemius muscle but more results would be necessary to establish this. The unexpectedly high value for ethanolamine plasmalogen in the gastrocnemius muscle from the 3 day infant likewise requires confirmation. Values for choline plasmalogen in the rectus abdominis and gastrocnemius muscle from the 2 and 3 day old neonates indicate that the increase in the proportion of choline plasmalogen continues after birth. In the rectus abdominis muscle this increase may be complete at 6 months, but continues longer in the gastrocnemius muscle so that in two older individuals of the control group it amounted to about $20 \%$ of the total muscle phospholipid.

Comparison of normal with dystrophic muscle does not reveal any significant differences in plasmalogen content. Although the mean choline plasmalogen content of the dystrophic gastrocnemius muscle is only about $50 \%$ of the normal, the difference is not significant because the normal mean is biased by the necessity of including in the control group tissue from adults whose muscle choline plasmalogen content was much higher than in the younger normals.
TABLE 3

PLASMALOGENS IN HUMAN SKELETAL MUSCLE (PHOSPHOLIPID-P AS \% TOTAL LIPID-P)

\begin{tabular}{|c|c|c|c|c|}
\hline Group & Muscle & Age & $\begin{array}{c}\text { Choline } \\
\text { plasma- } \\
\text { logen }\end{array}$ & $\begin{array}{c}\text { Ethanol- } \\
\text { amine } \\
\text { plasma- } \\
\text { logen }\end{array}$ \\
\hline $\begin{array}{l}\text { Normal } \\
\text { Dystrophic } \\
\text { Normal } \\
\text { Normal } \\
\text { Normal } \\
\text { Dystrophic } \\
\text { Normal } \\
\text { Normal } \\
\text { Normal }\end{array}$ & $\begin{array}{l}\text { Rectus } \\
\text { abdominis } \\
\text { Gastrocnemius } \\
\text { Foetal }\end{array}$ & $\begin{array}{l}4-12 \text { yr (5) } \\
3-5 \text { yr (5) } \\
6 \mathrm{mth} \\
2 \mathrm{~d} \\
5-40 \mathrm{yr}(5) \\
3-5 \mathrm{yr}(4) \\
15 \mathrm{mth} \\
3 \mathrm{~d} \\
10-20 \mathrm{wk}(5)\end{array}$ & $\begin{array}{l}8 \cdot 9 \pm 1 \cdot 0 \\
8 \cdot 3 \pm 1 \cdot 1 \\
8 \cdot 7 \\
6 \cdot 3 \\
14 \cdot 4 \pm 6 \cdot 7 \\
7 \cdot 8 \pm 1 \cdot 4 \\
6 \cdot 2 \\
4 \cdot 1 \\
1 \cdot 7 \pm 0.5\end{array}$ & $\begin{array}{l}14.9 \pm 1 \cdot 1 \\
15.7 \pm 1.6 \\
16 \cdot 8 \\
14.6 \\
12.9 \pm 1.4 \\
12.4 \pm 1.5 \\
12.8 \\
20 \cdot 1 \\
12 \cdot 5 \pm 1.6\end{array}$ \\
\hline
\end{tabular}

Values are given, where appropriate, as mean \pm standard deviation.

TOTAL CHOLESTEROL In Table 4 values are given for total cholesterol in normal, dystrophic, and immature muscle. Expressed in terms of phospholipid phosphorus there did not appear to be any consistent difference in cholesterol is content between rectus abdominis and gastro or cnemius muscles, nor between neonatal an $\$$ foetal muscle. The available data were therefor 8 pooled to give the means and standard deviation of the normal and dystrophic groups. Similarly? the immature group consists of both neonatap and foetal specimens.

The results show that the cholesterol conten of the dystrophic muscle is greater than norma and is similar to that of immature muscle.

OTHER NEUROMUSCULAR DISORDERS Table 5 s presents values for the sphingomyelin content of muscle biopsies from patients with neuromuscular disorders other than severe sex-linked Duchenne dystrophy. If the sphingomyelin content of other normal human muscles is similar to

TABLE 4

TOTAL CHOLESTEROL IN NORMAL, DYSTROPHIC, AND IMMATURE HUMAN MUSCLE $(\mu \mathrm{M} / \mu \mathrm{g}$ ATOM LIPID-P)

\begin{tabular}{ccc}
\hline Normal & Dystrophic & Immature \\
\hline $0.192 \pm 0.107(7)^{*}$ & $0.326 \pm 0.081(6)^{*}$ & $0.346 \pm 0.041(7)$ \\
\hline
\end{tabular}

Values are given as mean \pm standard deviation.

* Difference between normal and dystrophic means is significant with $0.05>\mathrm{P}>0.02$ 
TABLE 5

PHOSPHOLIPID IN MOUSE MUSCLE (PHOSPHOLIPID-P AS \% TOTAL LIPID-P)

\begin{tabular}{lccccc}
\hline Preparation & & $\begin{array}{c}\text { Sphingo- } \\
\text { myelin }\end{array}$ & CP & EP & $\begin{array}{c}\text { Cardio- } \\
\text { lipin }\end{array}$ \\
\hline Normal adult & $(8)$ & $3 \cdot 4 \pm 0 \cdot 8^{*}$ & $52 \cdot 8 \pm 1 \cdot 3^{*}$ & $26 \cdot 6 \pm 1 \cdot 1$ & $7 \cdot 4 \pm 0 \cdot 9$ \\
Dystrophic, adult & $(6)$ & $4 \cdot 8 \pm 0 \cdot 7^{*}$ & $48 \cdot 2 \pm 1 \cdot 3^{*}$ & $27 \cdot 8 \pm 1 \cdot 3$ & $8 \cdot 2 \pm 0 \cdot 7$ \\
Normal, 19 days $\dagger(1)$ & $2 \cdot 7$ & $51 \cdot 7$ & $29 \cdot 6$ & $6 \cdot 5$ \\
Normal, 5-6 days $\dagger(2)$ & $6 \cdot 5$ & $49 \cdot 4$ & $27 \cdot 4$ & $4 \cdot 5$ \\
& & & & & \\
\hline
\end{tabular}

$\mathrm{CP}=$ lecithin + choline plasmalogen $; \mathrm{EP}=$ total ethanolamine phospholipid.

* Difference between means for normal and dystrophic adults significant with $0.01>$ P. Other differences between normal and dystrophic adults are not significant $(P>0 \cdot 05)$.

+ Each preparation consisted of pooled muscle from six to eight animals.

that of the rectus abdominis and gastrocnemius muscle-that is, does not exceed 6 to $6.5 \%$-then only in the two patients with evidence of peripheral neuropathy and in the patient with a myopathy of unknown aetiology, possibly carcinomatous, is there an increase in muscle sphingomyelin.

\section{DISCUSSION}

NORMAL MUSCLE The amount of total phospholipid in the human gastrocnemius muscle is close to the figure for adults of $11.6 \mu$-mole $/ \mathrm{g}$ wet weight ( $360 \mu \mathrm{g} / \mathrm{g}$ wet weight) recently reported by Bruce and Svennerholm (1971) and values for individual phospholipids in the rectus abdominis and gastrocnemius are similar to those reported by Masoro, Rowell, and McDonald (1964) for monkey muscle and by Rouser et al. (1968) for human skeletal muscle except that the value for ethanolamine phospholipid in gastrocnemius muscle from the 5 to 40 year age group is somewhat lower. The amount of phospholipid in the cardiolipin fraction is higher than found by Rouser et al. (1968) even if it is taken to be equivalent to the sum of their diphosphatidyl glycerol and phosphatidic acid fractions, but similar to that found by Masoro et al. (1964). By contrast, Kunze and Olthoff (1970) in a report on normal and diseased human muscle find considerably more sphingomyelin in normal pectoral muscle than we have found in either gastrocnemius or rectus abdominis muscle. Moreover, unlike these authors, only trace amounts of lysolecithin were found in biopsy material and a maximum of $3 \%$ in tissue obtained post mortem. A further difference is that both gastrocnemius and rectus abdominis muscle contained an average of $6.7 \%$ and $7 \cdot 1 \%$ respectively of mono-phospho-inositol, an amount similar to that found in monkey muscle (Masoro et al., 1964) and in human muscle (Rouser et al., 1968), whereas Kunze and Olthoff (1970) do not report the presence of this phospholipid. It is not clear whether differences of analytical technique or in the particular muscle analysed are responsible for these discrepancies.

The plasmalogen content of both gastrocnemius and rectus abdominis was similar except that gastrocnemius from some older individuals contained rather large amounts of choline plasmalogen (up to $20 \%$ of the total phospholipid-P). The significance of this observation is not known.

The results for both rectus abdominis and gastrocnemius muscle from individuals of different ages show that, whereas at birth the phospholipid composition is rather similar to that of foetal muscle, a decrease in sphingomyelin and an increase in lecithin plus choline plasmalogen subsequently occurs. In the gastrocnemius muscle, there may also be some decrease in total ethanolamine phospholipid. In both muscles additionally there is an increase in the cardiolipin fraction and also in the percentage of choline plasmalogen, but these changes appear to occur both in the foetus and after birth.

Total cholesterol related to phospholipid-P also falls during maturation.

DUCHENNE MUSCULAR DYSTROPHY Results presented in Tables 2 and 4 suggest that in Duchenne dystrophy there is an interference with an aspect of muscle maturation which involves changes in the tissue concentrations of certain phospholipids and of cholesterol. Consequently the decline in sphingomyelin and cholesterol and the rise in the total of lecithin plus choline plasmalogen which normally occur during post-natal maturation are inhibited. In the dystrophic gastrocnemius muscle there is more ethanolamine than in the controls, an observation also consistent with an effect on maturation. On the other hand there does not appear to be any inter- 
ference with the increase in the cardiolipin fraction, nor in the choline plasmalogen (Table 3).

It is difficult to compare these results with those of Kunze and Olthoff (1970), since their values for phospholipids in normal muscle differ considerably from those reported here, except that, expressing their data on the same basis as used in this paper and assuming it includes choline plasmalogen, their values for the major component 'phosphatidyl choline' agree closely with data in this paper for lecithin plus choline plasmalogen.

Moreover their Duchenne patients belonged to the age group, 6 to 18 years, which presumably included some advanced cases in whom the tissue phospholipid pattern might not be the same as at an earlier stage of the disease. Consequently they report a fall both in the 'phosphatidyl choline' and 'phosphatidyl ethanolamine' fractions, whereas the present report indicates that there is a rise in sphingomyelin, a fall in the total lecithin (phosphatidyl choline) plus choline plasmalogen, and in the gastrocnemius but not in the rectus abdominis muscle, a rise in total ethanolamine phospholipid-that is, phosphatidyl ethanolamine plus ethanolamine plasmalogen.

In hereditary muscular dystrophy of the mouse, similar lipid changes occur. Table 5 presents data recalculated from Hughes (1965) together with figures for immature mice suggesting that there may also be an interference with maturation in the animal disorder. The value for sphingomyelin in the dystrophic muscle is intermediate between that of the normal adult and the 5 to 6 day old animals, so that the situation is analogous to that in the normal and dystrophic human gastrocnemius muscle. By 19 days the normal mouse muscle phospholipid pattern except for the ethanolamine phospholipid is similar to that of the adult animal.

OTHER HUMAN MUSCLE DISORDERS Because similar phospholipid changes occur both in human Duchenne and in mouse dystrophy, they are clearly not specific but may indicate the presence of common pathological mechanisms. Consequently, it would be of interest to know if such changes occur in other forms of human neuromuscular disease. For this reason muscle biopsies from patients with a variety of muscle disorders were compared (Table 6).

Because of the rather wide range of muscles chosen on clinical grounds for biopsy, it has so far not been possible to match the pathological specimens with adequate normal controls.

TABLE 6

MUSCLE SPHINGOMYELIN IN HUMAN NEUROMUSCULAR DISORDER

\begin{tabular}{|c|c|c|}
\hline Diagnosis & Muscle & $\begin{array}{l}\text { Sphingomyelin- } P \\
\text { as } \% \text { total lipid- } P\end{array}$ \\
\hline Normal (5) & $\begin{array}{l}\text { Rectus } \\
\text { abdominis }\end{array}$ & $4 \cdot 8 \pm 0 \cdot 5$ \\
\hline Normal (5) & Gastrocnemius & $5 \cdot 4 \pm 1 \cdot 1$ \\
\hline PMD, Becker type & Gastrocnemius & $5 \cdot 9$ \\
\hline PMD, ? Becker type & $\begin{array}{l}\text { Tibialis } \\
\text { anterior }\end{array}$ & $5 \cdot 6$ \\
\hline PMD, limb girdle & Vastus lateralis & $5 \cdot 0$ \\
\hline PMD, limb girdle & Vastus lateralis & $4 \cdot 2$ \\
\hline PMD, facioscapulohumeral & Deltoid & $3 \cdot 7$ \\
\hline Polymyositis & Deltoid & $6 \cdot 0^{*}$ \\
\hline Polymyositis & Quadriceps & $3 \cdot 5^{*}$ \\
\hline Polymyositis & Biceps & $5 \cdot 6 \dagger$ \\
\hline Central core disease & $\begin{array}{l}\text { Tibialis } \\
\text { anterior }\end{array}$ & $4 \cdot 5$ \\
\hline Myopathy, ? carcinomatous & Quadriceps & $7 \cdot 8$ \\
\hline Peripheral neuropathy & $\begin{array}{c}\text { Peroneus } \\
\text { longus }\end{array}$ & $8 \cdot 4 \ddagger$ \\
\hline Peripheral neuropathy & Quadriceps & $8 \cdot 0$ \\
\hline
\end{tabular}

* Histology inconclusive.

+ Histology typical.

$\ddagger$ On steroids.

Consequently there must be doubt concerning the proper basis of comparison. For preliminary assessment it has been assumed that other normal human muscles contain the same amount of sphingomyelin as do the rectus abdominis and gastrocnemius muscles, even if this may not be true for other phospholipids. A report by Owens and Angelini (1970) provides some justification for this. They found that whereas the lecithin plus choline plasmalogen, ethanolamine phospholipid, and cardiolipin content of different muscle types varied according to whether they are fast or slow, the amount of sphingomyelin did not.

On this basis, only in two patients with evidence of peripheral neuropathy, and in a patient $\frac{D}{0}$ with a myopathy of unknown origin, although the possibility of carcinoma was considered, did 0 the muscle sphingomyelin appear to be raised. $N$ 
Prolonged steroid therapy, since it can induce myopathic changes, could have affected the phospholipid pattern in one of the individuals with peripheral neuropathy.

Any conclusions must necessarily be tentative, but some of the alterations in muscle phospholipids seen in Duchenne dystrophy do not seem to occur in all forms of muscle disease. That changes can occur in acquired neuronal disorder suggests that the muscle phospholipid pattern, like various other biochemical parameters may be under the influence of the motor neurone.

I thank Mr. D. Young and Dr. V. Dubowitz for help in obtaining biopsies from patients with Duchennetype muscular dystrophy. The work was supported by the Muscular Dystrophy Group of Great Britain.

\section{REFERENCES}

Bruce, Å., and Svennerholm, L. (1971). Skeletal muscle lipids. I. Changes in fatty acid composition of lecithin in man during growth. Biochimica et Biophysica Acta, 239, 393-400.

Hughes, B. P. (1965). Phospholipids in normal and dystrophic mouse muscle. In Research in Muscular Dystrophy. The Proceedings of the Third Symposium held in London in 1965, pp. 187-197. Pitman Medical: London.

Kunze, D., and Olthoff, D. (1970). Der Lipidgehalt menschlicher Skelettmuskulatur bei primären und sekundären Myopathien. Clinica Chimica Acta, 29, 455-462.

Masoro, E. J., Rowell, L. B., and McDonald, R. M. (1964). Skeletal muscle lipids. 1. Analytical method and composition of monkey gastrocnemius and soleus muscles. Biochimica et Biophysica Acta, 84, 493-506.

Owens, K. (1966). A two-dimensional thin-layer chromatographic procedure for the estimation of plasmalogens. Biochemical Journal, 100, 354-361.

Owens, K., and Angelini, C. (1970). Phospholipid composition of slow (soleus) and fast (extensor digitorum longus) muscles of the mouse. Physiological Chemistry and Physics, 2, 477-482.

Owens, K., and Hughes, B. P. (1970). Lipids of dystrophic and normal mouse muscle: whole tissue and particulate fractions. Journal of Lipid Research, 11, 486-495.

Rouser, G., Nelson, G. J., Fleischer, S., and Simon, G. (1968). Lipid composition of animal cell membranes, organelles and organs. In Biological Membranes, pp. 5-69. Edited by D. Chapman. Academic Press: London.

Zlatkis, A., Zak, B., and Boyle, A. J. (1953). A new method for the direct determination of serum cholesterol. Journal of Laboratory and Clinical Medicine, 41, 486-492. 